\title{
Perfil dos atropelamentos na cidade de Maceió no ano de 2007
}

\section{Profile of trampling in the city of Maceió in the year 2007}

DOI: $10.46814 / \operatorname{lajdv3n3-041}$

Recebimento dos originais: 01/052021

Aceitação para publicação: 31/06/2021

José Anselmo Nunes Brasil

Doutor em Sociologia, Sociólogo da Universidade Estadual de Ciências da Saúde de Alagoas -

(UNCISAL), Maceió, AL, Brasil.

E-mail: anselmobrasil@yahoo.com.br

\section{Marcela Maria Correia Santos}

Acadêmicas do $6^{\circ}$ ano da graduação em Medicina da UNCISAL, Maceió, AL, Brasil.

\begin{abstract}
RESUMO
O presente trabalho consiste em traçar o perfil dos atropelamentos, buscando explicar e compreender o problema desse tipo de acidente de trânsito, atendidos pelo Serviço de Atendimento Móvel de Urgência (SAMU), Maceió/AL no ano de 2007. Consiste em um estudo epidemiológico transversal e retrospectivo. Foram analisadas 280 fichas, correspondentes ao período de janeiro a dezembro de 2007. Das fichas analisadas, 198 corresponderam a Unidade de Suporte Básico (USB) e 82 a Unidade de Suporte Avançada (USA). O veículo de atropelamento mais acometido foi os automobilísticos $(56,07 \%)$. As vítimas caracterizaram-se por serem, em sua maioria, jovens e adultos $(60,71 \%)$, do sexo masculino $(58,9 \%)$. O domingo foi o dia com o maior número de atropelamentos $(17,85 \%)$ A maioria dos acidentes (57,13\%) ocorreu no período da tarde/noite (12 ás 23:59h),observando um pico da incidência $(28,27 \%)$ no período entre 17 e 21 horas.Os distritos com maior prevalência foram o segundo e o quinto $(33,21 \%)$. Este estudo, além de propiciar mais dados epidemiológicos que poderão servir para auxiliar em políticas específicas para segurança do pedestre e do motorista no trânsito, visa conscientizar e alertar as pessoas da importância de medidas de prevenção para minimizar este grave problema de saúde populacional na cidade de Maceió/AL.
\end{abstract}

Palavras-chave: Atropelamento, Acidente de trânsito, Pedestre, Maceió.

\section{ABSTRACT}

The present work is to trace the profile of being run over, trying to explain and understand the problem of this kind of traffic accident, attended by Service at Mobile Emergency Care (EMS), Maceió / AL in 2007. It consists of an epidemiological study retrospective and cross .Two hundred eighty files were analyzed, covering the period from January to December 2007. From the records reviewed, 198 corresponded to Basic Support Unit (USB) and 82 Advanced Support Unit (USA). The highest number of accidents with pedestrian was involved the automobile (56.07\%). The victims were characterized as being mostly young people and adults $(60.71 \%)$, male $(58.9 \%)$.Sunday was the day with the highest number of pedestrian accidents $(17,85 \%)$. The majority of accidents $(57,13 \%)$ occurred in the afternoon/evening (12-23:59 pm),observing a peak incidence $(28,27 \%)$ in the period between 17 and 21 horas. Os districts with the highest prevalence were the second and fifth $(33.21 \%)$. This study, besides providing more epidemiological data that could be used to assist with specific policies for pedestrian safety and driver in traffic, will educate and alert the warn people of the importance of preventive measures to minimize this serious health problem in the city population Maceió/Al. 
Key Words: Traffic Accidents, Running over, Pedestrian, Maceió.

\section{INTRODUÇÃO}

A predominância do transporte rodoviário no Brasil, decorrente do modelo e da acelerada urbanização, provocaram a valorização social do automóvel em nosso país acarretando um grande crescimento no número de veículos nas cidades brasileiras ${ }^{1}$.

Sem uma infra-estrutura correspondente que pudesse absorver tal volume de automóveis e, principalmente, sem a conscientização do risco deste tipo de veículos para a população, nas cidades e rodovias os acidentes no trânsito passaram a ser uma das principais causas de invalidez, morte e elevação do custo da saúde pública no Brasil ${ }^{1}$.

Em relação aos custos com os acidentes de trânsito, o Estado brasileiro gasta, aproximadamente, dez bilhões de dólares por ano com os acidentes de trânsito, no que se refere aos gastos com tratamento das vítimas, com a Previdência Social e com o investimento do governo no cidadão que morre prematuramente no trânsito ${ }^{1}$.

Enquanto em países como os Estados Unidos da América (EUA), Canadá e algumas nações européias a mortalidade no trânsito apresentava tendência crescente até o início dos anos 1960, passando então a cair progressivamente, no Brasil, inversamente, a curva de vítimas fatais no trânsito inicia uma ascensão na segunda metade do século XX. O número de mortos aumentou em seis vezes entre 1961 e 2000 e o de feridos foi multiplicado por $15^{2}$.

No Brasil, conforme informações contidas na Política Nacional de Trânsito do Departamento Nacional de Trânsito (DENATRAN, 2004), a cada ano mais de 33 mil pessoas são mortas e cerca de 400 mil ficam feridas ou inválidas em ocorrências de trânsito ${ }^{3}$.

O comprometimento de setores ligados à saúde na investigação das causas dos conflitos no trânsito - assunto historicamente relegado às áreas de transportes e segurança pública - demorou-se em se manifestar de maneira mais intensa até assumir que, como as cardiopatias, o câncer e as doenças cerebrovasculares, os traumas adquiridos no trânsito devem ser entendidos como um problema que responde bem a intervenções eficientes ${ }^{2}$.

Em Alagoas, Gonçalves et al (2006) em estudo sobre acidentes de trânsito em Maceió destaca que os atropelamentos não constam no banco de dados do Detran-AL e o Ministério da Saúde, menciona apenas atropelamentos na capital com taxa de mortalidade de aproximadamente 10,3/100 mil habitantes ${ }^{4,5}$.

Desta forma, observou-se a necessidade de preencher a escassez na literatura sobre os atropelamentos na cidade de Maceió, AL, realizando um estudo para conhecer de modo dinâmico o 
perfil dos atropelamentos em Maceió. Estudo que contribuirá com a disseminação de informações através dos dados epidemiológicos e poderá auxiliar em políticas de prevenção específicas e eficientes para minimizar este grave problema de saúde populacional Alagoana.

\section{MÉTODOS}

Estudo epidemiológico transversal e retrospectivo.

Foram analisadas todas as fichas do SAMU de pedestres vítimas de acidente de trânsito correspondentes ao período de janeiro a dezembro de 2007, totalizando 280. Os critérios de inclusão adotados foram todas as vítimas de atropelamento de ambos os sexos e de todas as faixas etárias que receberam atendimento do Serviço de Atendimento Móvel e Urgência (SAMU) no ano de 2007, enquanto os critérios de exclusão foram as fichas que não preenchiam os critérios de inclusão.

As variáveis estimadas da pesquisa foram: sexo; idade; horário, dia; distrito sanitário da ocorrência e tipo do veículo do atropelamento (carro, moto, caminhão, ônibus, bicicleta, carroça).

Por se tratar de uma pesquisa retrospectiva que utilizou dados secundários, o pesquisador não teve contato direto com os sujeitos da pesquisa e manteve todo o cuidado em não utilizar e expor qualquer variável que identificasse os sujeitos pesquisados, portanto, garantiu confidencialidade e minimização de risco de identificação dos pacientes. Por estas razões, obteve-se a dispensa de Termo de Consentimento Livre e Esclarecido

Todos os dados foram armazenados em planilhas do Microsoft Excel 2000 para Windows. Posteriormente, o resultado encontrado foi consequente à análise quantitativa baseada em frequência absoluta e proporções das notificações colhidas no arquivo do Serviço de Atendimento Móvel e Urgência (SAMU) no período de janeiro a dezembro de 2007.

A escolha pelo enfoque quantitativo deveu-se ao fato do mesmo possibilitar a coleta sistemática de informações numéricas, através de condições de muito controle e de uma análise das informações a partir da estatística6 6

\section{RESULTADOS}

Das 280 fichas coletadas e analisadas do SAMU, 198 correspondem a Unidade de Suporte Básico (USB) e 82 a Unidade de Suporte Avançada (USA) com vítimas de atropelamento em estado grave. As vítimas de atropelamentos caracterizaram-se por serem jovens/adultos do sexo masculino (58,59\%), conforme Gráfico 1 e na faixa etária entre 10-49 anos (60.71\%),conforme Gráfico 2 .

A maioria das vítimas de atropelamento na cidade de Maceió teve o carro de passeio como principal objeto de colisão $56,07 \%$, seguida por motocicleta $25 \%$, caminhão/ônibus $9.28 \%$, e bicicleta, 
carroça movida por tração animal (seguimento outros) $4.64 \%$. Ressalta-se que $5 \%$ das fichas não foram preenchidas no campo do tipo do objeto de colisão com o pedestre, observado no Gráfico 3.

Em relação aos horários de atropelamento a prevalência foi entre as 12 e 23:59 horas (tarde/noite) com 57.13\%, seguida pelo horário de 06 as $11: 59$ horas com $13.21 \%$ e por último a madrugada com 3.57\%.Destaca-se que $22.19 \%$ das fichas não continham o horário do acidente. (Gráfico 4).

Porém, o pico da incidência de atropelamentos ocorreu entre 17 e 21 horas, com $28.57 \%$ dos casos. Neste horário observou-se que $73.75 \%$ de pedestres atropelados estavam na faixa etária de 10 49 anos, com predominância de colisões por carro (53.75\%), moto (31.25\%), bicicleta (8.75\%), caminhão/ônibus $(3.75 \%)$. Vale ressaltar a bicicleta como um importante meio de transporte utilizado na cidade de Maceió.

No outro extremo estavam os horários entre 0 ás 5:59 horas com 3,57\%, cuja vítimas do sexo masculino foram acometidas em 3,21\% dos casos; ao passo em que, entre pedestres do sexo feminino, notou-se um percentual de ocorrência 10 vezes menor $(0,35 \%)$ do que o registrado para os homens. Esta diferença relevante pode estar relacionada aos padrões culturais vigentes mencionados anteriormente.

Verificou-se que a maior frequiência de atropelamentos ocorreu durante a semana (segundafeira à sexta-feira) com $65.73 \%$ e o final de semana (sábado e domingo) com apenas dois dias apresentou elevado percentual 37.27\% (Gráfico 5).

A ocorrência de pedestres atropelados apresentando hálito etílico foi de $15,35 \%$ e de hálito de cola $1,42 \%$, totalizando $16.77 \%$. Durante os finais de semana foi verificado hálito etílico em $8,57 \%$ dos pedestres atropelados e durante a semana a incidência foi de $8.2 \%$.

À distribuição espacial dos atropelamentos na cidade de Maceió foi prevalente no segundo e quinto distrito ambos com $33.21 \%$, seguida pelo primeiro e sétimo, ambos com 15\%, o terceiro com $12.5 \%$, o quarto com $12.14 \%$ e por último o sexto distrito com $3.57 \%$.

\section{DISCUSSÃO}

As vítimas de atropelamentos na cidade de Maceió atendidas pelo SAMU caracterizaram-se, em sua maioria, por serem adultos jovens (60.71\%), do sexo masculino (58.59\%). Dados semelhantes foram obtidos por Santos e Soler (2007) quando investigaram as vítimas do trânsito em São José do Rio Preto/SP, onde 72,9\% dos indivíduos eram desse sexo ${ }^{7}$. Semelhante resultado foi detectado por Oliveira, Mota e Costa (2008), trabalhando a evolução temporal dos acidentes de trânsito ocorridos em Salvador/BA, que detectaram mais de $70 \%$ do total de vítimas do sexo masculino ${ }^{8}$. Resultados semelhantes, aos autores ora citados, foram encontrados por Lima (2005) ao investigar algumas das 
características das vítimas fatais de acidente de trânsito na cidade metropolitana de Belém/PA, quando $80,9 \%$ eram homens ${ }^{9}$. E o mesmo a literatura internacional especializada indica que a incidência dos atropelamentos atingem os homens em uma proporção 2 a 3 vezes maior que as mulheres ${ }^{10}$.

Apesar de não observado o comportamento da vítima, muitos estudos tendem a explicar essa prevalência masculina pelo seu estereótipo. Todos esses estudos levam a constatar que a superioridade do sexo masculino é um traço fortemente característico desse tipo de evento, sinalizando mais uma vez o fato da exposição do homem, além do comportamento mais agressivo desse grupo no trânsito. Há de se considerar também que determinantes sociais e culturais, cristalizados na noção de gênero, os expõem a maiores riscos na condução dos veículos, como velocidades excessivas, manobras arriscadas e consumo do álcool ${ }^{11}$.

Concordando com os dados de Ribas Filho (2002), outros autores encontraram que as causas externas atingem $60 \%$ dos indivíduos jovens do sexo masculino ${ }^{12}$.

A vulnerabilidade dessa população jovem é confirmada no nosso estudo colaborando com os dados obtidos em várias pesquisas. Um estudo realizado por Bastos, Andrade e Soares (2005), por exemplo, ao caracterizarem as vítimas de acidentes de trânsito pelo Sistema Integrado de Atendimento ao Trauma e Emergência (SIATE) de Londrina /PR no período de 1997 a 2000, evidenciaram que houve prevalência da faixa etária entre $20-29$, com $34,9 \%, 36,5 \%, 34,2 \%$ e $33 \%$ respectivamente ${ }^{13}$.

Tomando como base esses dados, alertamos que o fato dessas vítimas serem jovens, em plena idade produtiva, possa comprometer, em algumas situações, a renda familiar. Isso muitas vezes ocorre porque um grande número desses indivíduos deixa de trabalhar temporária ou permanentemente, em virtude das conseqüências de suas lesões, diminuindo a qualidade de vida tanto do paciente como da sua família e contribuindo para a diminuição da força de trabalho futuro ${ }^{8,12}$.

Desta forma, analisando as informações anteriores, pode-se afirmar que os acidentes de trânsito representam uma pesada carga tributária para a economia mundial, para a vítima e para as famílias, que muitas vezes deixam de receber o apoio financeiro para o seu sustento devido às incapacidades geradas pelo trauma, chegando a atingir, em algumas situações, a linha de pobreza ${ }^{6}$.

Alguns autores associam esta predominância de jovens nos acidentes de trânsito à imaturidade, no que se refere á detecção e prevenção da possibilidade de conflitos no trânsito e ao excesso de autoconfiança na condução do veículo, levando-os a correrem maiores riscos ${ }^{13,14}$. Montal acrescenta também que a sensação de invulnerabilidade dos jovens causa neles a impressão de imortalidade, fruto da falta de consciência dos riscos dos acidentes ${ }^{14}$.

No entanto, vale ressaltar que os acidentes de trânsito são preveníveis em $100 \%$ das suas ocorrências, sendo, na maioria das vezes decorrentes da imprudência e negligência dos usuários, motoristas e pedestres em relação a leis e normas de segurança, a precária conservação das estradas, 
ao longo tempo de uso da frota (mais de doze anos) e sua manutenção inadequada; as condições dos veículos e as falhas humanas ${ }^{15,16}$.

A maior parte dos atropelamentos em Maceió ocorreu no período de 12h às 23:59 horas $(57,13 \%)$,sendo $28,92 \%$ do período da tarde, $12 \mathrm{~h}$ ás $17 \mathrm{~h} 59 \mathrm{~min}$ e $28,21 \%$ a noite, $18 \mathrm{~h}$ ás $23 \mathrm{~h} 59 \mathrm{~min}$.No outro extremo estavam os horários entre 0 ás 5:59 horas com 3,57\%,cuja vítimas do sexo masculino foram acometidas em 3,21\% dos casos; ao passo em que, entre pedestres do sexo feminino, notou-se um percentual de ocorrência 10 vezes menor $(0,35 \%)$ do que o registrado para os homens. Esta diferença relevante de sexo pode estar relacionada aos padrões culturais vigentes mencionados anteriormente.

Bastos, Andrade e Soares (2005), analisando a distribuição das vítimas por horário de ocorrência do acidente em Londrina/Paraná, nos anos de 1998 a 2000, verificaram que a maior concentração dos acidentes ocorreu nos horários da tarde, das 12h às 17h59min, e da noite, das $18 \mathrm{~h}$ ás $23 \mathrm{~h} 59 \mathrm{~min}^{13}$.

Contudo, em Maceió o pico da incidência de atropelamentos ocorreu entre 17 e 21 horas, com 28.57\% dos casos, o que pode ser explicado pelo grande volume de veículos e pedestres em trânsito neste horário, quando boa parte da população urbana retorna do trabalho/ estudo às suas residências ou dá início a outras atividades ${ }^{6}$, como sugerem os $73,75 \%$ de pedestres atropelados na faixa etária de 10 49 anos. Neste horário, verificou uma predominância em atropelamentos por carro $(53,75 \%)$, moto $(31,25 \%)$, bicicleta $(8,75 \%)$, caminhão/ônibus $(3,75 \%)$. Vale ressaltar a bicicleta como um importante meio de transporte utilizado na cidade de Maceió.

Pode-se explicar este pico de horário também através dos estudos, que enfatizam ainda que a noite é o período de maior incidência de vítimas, provocando acidentes com maior gravidade, em virtude de fatores ligados ao meio ambiente como a menor visibilidade aos usuários da via pública e como o excesso de velocidade, o desrespeito aos semáforos e o uso de álcool/drogas ${ }^{13}$.

Em relação aos dias da semana, verificou-se uma incidência maior dos atropelamentos nos finais de semana (sábado e domingo) totalizando 37,27\%. Confirmando uma realidade semelhante a da nossa pesquisa, Scalassara, Souza e Soares em 1992 no município de Maringá/Paraná, já evidenciaram uma elevada predominância nos finais de semana, $54,8 \%$ dos acidentes fatais ${ }^{17}$. Pereira e Lima (2006), ao tentarem caracterizar as ocorrências de acidentes de trânsito em Porto Alegre/RS, também verificaram que as ocorrências concentravam-se nos finais de semana ${ }^{18}$. Oliveira, Mota e Costa (2008) reafirmaram essa tendência, obtendo como resultado 35\% das ocorrências entre sábado e domingo ${ }^{8}$.

A ocorrência de pedestres atropelados apresentando hálito etílico e de cola foi de $16,77 \%$. Entretanto, a associação entre consumo de álcool e acidentes seguidos de trauma com pedestres é 
relevante. Por exemplo, num estudo em 13 centros de tratamento de trauma em Los Angeles, nos Estados Unidos, durante o ano de 2003, observou-se que em 1.042 pacientes avaliados, 34\% haviam consumido álcool antes da ocorrência, sendo os pedestres e ciclistas o grupo de pacientes com mais complicações físicas e óbitos que os demais. Dessa maneira, há de salientar a necessidade de implantação de programas educativos, bem como de políticas de saúde direcionadas para essa população $^{19}$.

Estudos comprovam que o consumo de álcool dificulta a tomada de decisões e entorpece as habilidades psicomotoras do condutor e do pedestre, provocando modificações importantes, ás vezes, vitais, nos tempos de reação de um indivíduo ${ }^{19}$.

Desta forma, no que se refere aos acidentes de trânsito que foram influenciados pelo uso de bebidas alcoólicas, fator passível de prevenção efetiva, é essencial que se chame a atenção para a necessidade de uma maior conscientização e responsabilização de todos os envolvidos ${ }^{6,19}$.

Outro aspecto importante, é que se faz necessário rever as condutas do SAMU, quanto ao preenchimento das fichas das vítimas de atropelamentos, já que 22,19\% da fichas não continham o horário do acidente. Outros campos, objeto de colisão, idade da vítima também contiveram falhas nas analises das fichas da SAMU. Ressalta-se que a USA não preencheu 76,82\% do horário dos 82 atropelamentos atendidos e a USB teve 3,12\% das 192 ocorrências de atropelamento.

Nesse contexto, nota-se a necessidade de avançar na implantação de políticas públicas que contribuam para a alocação de mais recursos nessa área, otimizando a integração das ações e a melhor conscientização da população quanto à necessidade de constituir ambientes e comportamentos mais seguros e saudáveis.

\section{CONCLUSÃO}

Os acidentes de trânsito representam um problema de saúde pública em todo o mundo. As estatísticas de trânsito mostram números cada vez mais alarmantes. Deve-se ressaltar que a prevalência de adultos jovens, nos atropelamentos, repercute de forma importante sobre a população ativa. Portanto, essa realidade reforça a implementação de forma mais agressiva de campanhas educativas sobre as normas de trânsito, orientação de pedestres e motoristas e conscientização da população sobre os perigos provocados pelos automóveis. Esperamos que o nosso trabalho incentive novos estudos e sirva como ferramenta para elaboração de políticas, visando reduzir tais índices e, conseqüentemente, diminuir as taxas de invalidez e mortalidade por acidente de trânsito. 


\section{REFERÊNCIAS BIBLIOGRÁFICAS}

1. Fagundes-Pererira, WJ; Tanure, R.; Petroianu, A. Conhecimento das leis de trânsito por vítimas de atropelamento em Belo Horizonte em 1997. Medicina, Ribeirão Preto. 1999; (32): 189-192.

2. Paviano Filho, RV. Morbimortalidade no trânsito: limitações dos processos educativos e contribuições do paradigma da promoção da saúde ao contexto brasileiro. Epidemiol. Serv. Saúde, Brasília. 2009; 18(4): 375-384.

3. DENATRAN: Dados estatísticos de acidentes de trânsito. Ministério da Justiça - Sistema Nacional de estatística de Trânsito - SINET. Brasília, DF, 1995.

4. Gonçalves, C.F.S. et al. Trabalho de Iniciação Científica ProBic/Uncisal/ Fapeal, Universidade Estadual de Ciências da Saúde de Alagoas - Uncisal, Maceió, 2006.

5. Sistema Nacional de Vigilância em Saúde: Relatório de situação: Alagoas / Ministério da Saúde, Secretaria de Vigilância em Saúde. 2. ed. - Brasília: Ministério da Saúde, Série. Projetos, Programas e Relatórios, 24p, 2006.

6. Ramos, CS. Caracterização do acidente de trânsito e gravidade do trauma: um estudo em vítimas de um Hospital de Urgência em Natal/RN. [Dissertação de Mestrado], 2008.

7. Santos, MR; Soler, ZASG. Vítimas de trânsito em São José do Rio Preto,São Paulo.Epidemiologia e Serviços de Saúde.2007; 16(2).

8. Oliveira, ZC; Mota, ELA; Costa, MCN. Evolução dos acidentes de trânsito em grande centro urbano, 1991-2000. Cad. Saúde Pública, Rio de Janeiro. 2008; 24(2): 364-372.

9. Lima, AG. Análise estatística das vítimas fatais de acidentes de trânsito ocorridos na região metropolitana de Belém no ano de 2003. (Monografia). Universidade Federal do Pará, Belém, 2005.

10. Acidentes de Trânsito - Pedestres - Caracterização dos pacientes. www.sarah.br/paginas/prevencao/po/02_05_acid_trans_pedest.pdf -

11. Andrade, S.; Mello Jorge, MHP. Características das vítimas por acidente de transporte terrestre em município da Região Sul do Brasil. Rev. Saúde Pública, 2001; 17(6): 1449-1456.

12. Ribas Filho, JM et al. Estudo de prevalência dos óbitos por trauma nos principais pronto-socorros de Curitiba no período de abril/2001 a abril/2002. Revista Médica do Paraná,Curitiba. 2002; 60(2).

13. Bastos, YGL; Andrade, SM; Soares, DA. Características dos acidentes de trânsito e das vítimas atendidas em serviço pré-hospitalar em cidade do Sul do Brasil, 1997/2000. Cad. Saúde Pública, Rio de janeiro. 2005; 21(3): 815-822.

14. Montal, JHC. O médico, o jovem e o trânsito: acidentes de trânsito no Brasil. Revista Abramet São Paulo. 2001; (39): 48-9.

15. Marin, L.; Queiroz, M.S. A atualidade dos acidentes de trânsito na era da velocidade; uma visão geral. Cad. Saúde Pública, Rio de Janeiro. 2000; 16(1):7-21. 
16. Esteves, R; Montalvão, CR; Valle-Real, M. Por uma cultura do trânsito. Revista da Abramet.2001;(36): 31-35.

17. Scalassara MB, de Souza RK, Soares DF. Características da mortalidade por acidentes de trânsito em localidade da Região Sul do Brasil. Rev. Saúde Pública. 1998; 32 (2):125-32.

18. Pereira, WAP; Lima, MADS. Atendimento pré-hospitalar: caracterização das ocorrências de acidente de trânsito. Acta Paul Enferm. 2006; 19(3):79-83.

19. Segatto, ML; Souza e Silva, R; Laranjeira, R; PinskY, I. O impacto do uso de álcool em pacientes admitidos em um pronto-socorro geral universitário. Revista Psiquiatria Clínica. 2008; 35 (4):138-43. 


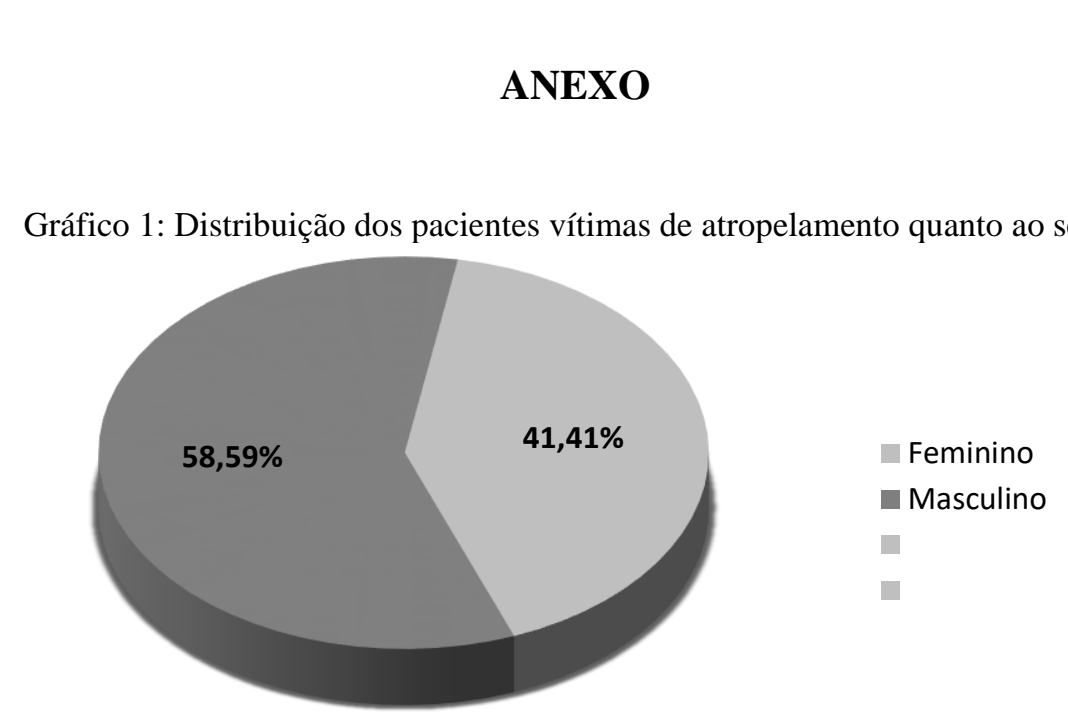

Fonte: Samu-AL

Gráfico 2: Distribuição do número de pacientes vítimas de atropelamento por faixa etária.

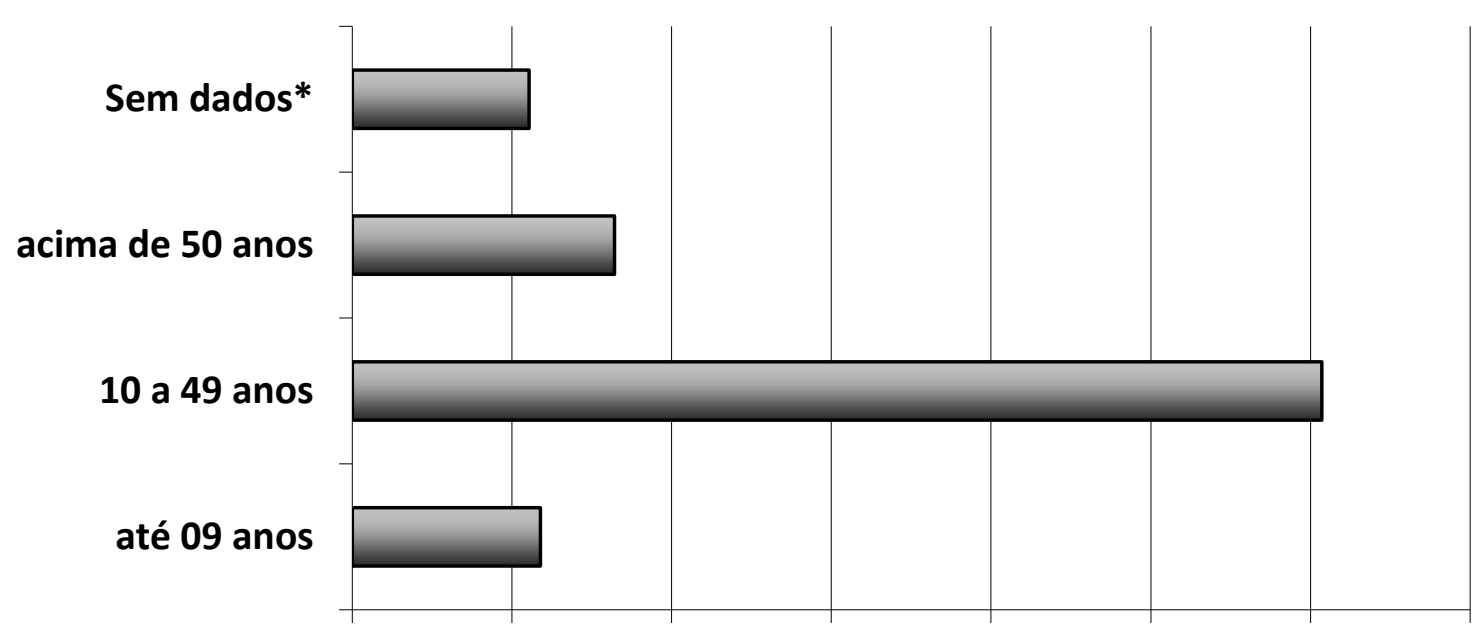

1900ral 1900ral 1900ral 1900ral 1900ral 1900ral 1900ral 1900ral

Fonte: Samu-AL 
Gráfico 3: Distribuição dos atropelamentos quanto ao tipo de veículo em colisão.

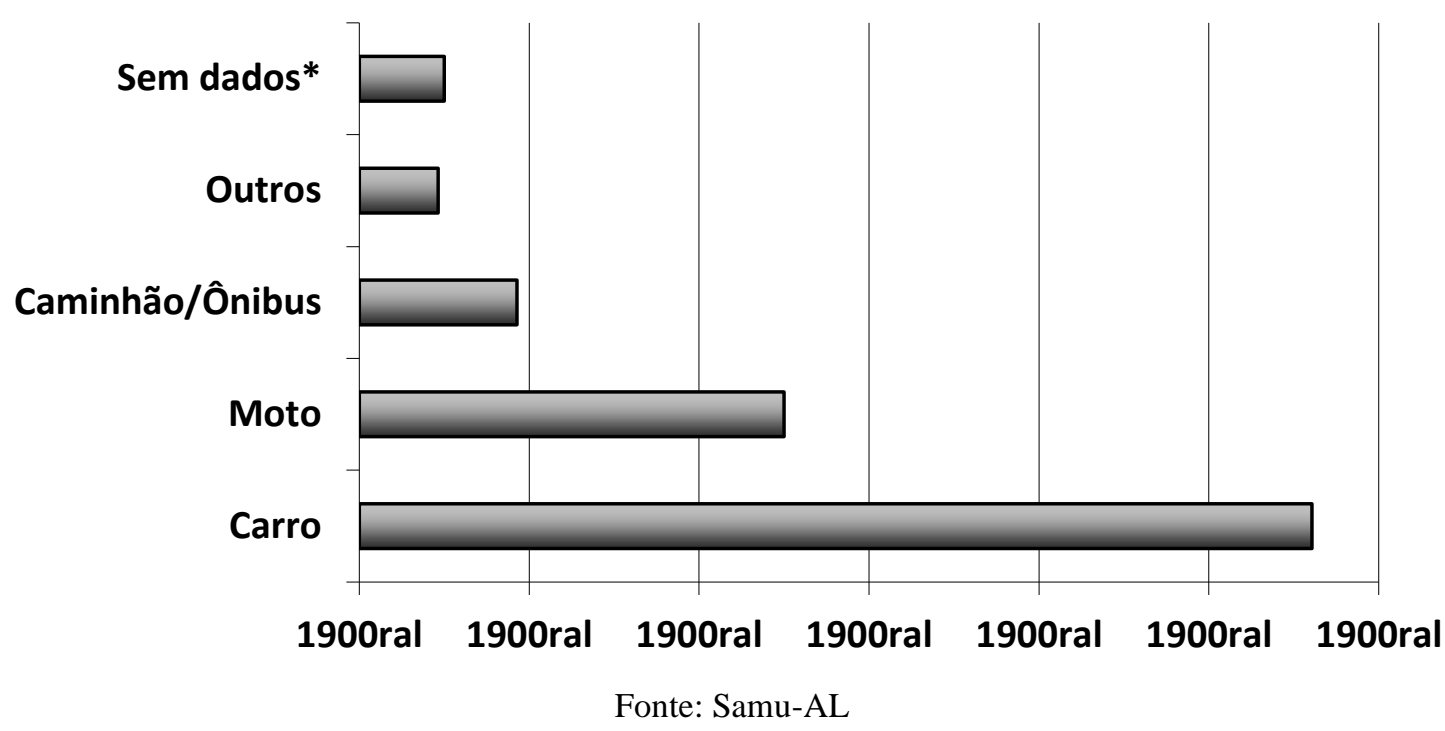

Gráfico 4: Distribuição dos atropelamentos em relação ao período do dia.



Fonte: Samu-AL 
Gráfico 5: Distribuição dos atropelamentos em relação ao dia da semana.

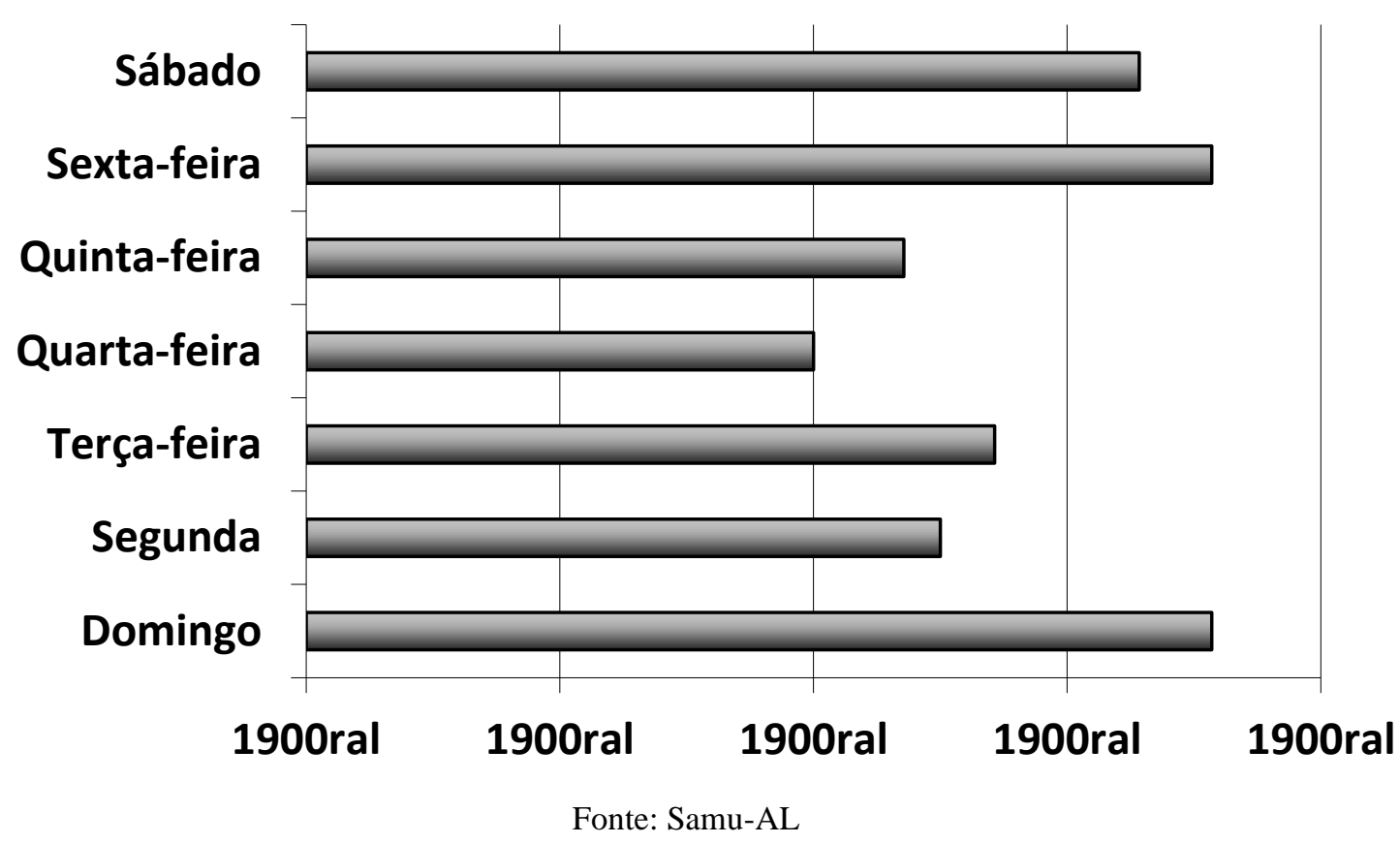

